Miquel Bartual, Mijo.

Profesora asociada, UPV, Departamento de Escultura.

\title{
Modificaciones del concepto de lo salvaje en el Antropoceno.
}

\section{Modifications on the Concept of Wilderness in the Anthropocene.}

TIPO DE TRABAJO:

Comunicación.

PALABRAS CLAVE:

Antropoceno, salvaje, duelo ecológico, post-humanismo, arte.

KEY WORDS:

Anthropocene, wilderness, ecological grief, post-humanism, art.

RESUMEN.

En un momento de crisis sistémica como en el que nos encontramos, la lucha contra el cambio climático es una de las prioridades a las que debemos hacer frente, incluso por delante del anunciado agotamiento de los combustibles fósiles y la consecuente transición hacia el consumo de energías renovables. Desde un análisis multifactorial, todas las disciplinas coinciden en la urgencia del cambio y a escala global, esta convicción debería transformar igualmente nuestros modos de vida integrando criterios ecosistémicos en cualquier nuevo plan.

Reconocer el Antropoceno como el nuevo marco natural así como los efectos devastadores que de ello se derivan a escala planetaria nos permite hacer una relectura epocal de lo salvaje, invirtiendo su sentido, ya que en vez de corresponder a la antigua acepción colonialista del Otro inculto, se aplica a nuestra civilización que en teoría se encuentra en su punto máximo de desarrollo en términos de educación y recursos : nunca antes tantos tuvieron tanto ni pudieron aprender tanto.

Hallándonos en este punto de inflexión, nos preguntamos qué puede hacer el arte al respecto, cómo podría contribuir a la visibilización de nuestra urgencia y a la vinculación con el territorio, mediante la necesaria elaboración del duelo ecológico que el reconocimiento de esta nueva era nos provoca, evitando la parálisis y/o la huída hacia delante como estrategias de evasión más inmediatas.

\section{ABSTRACT.}

At a time of systemic crisis such as the one we are in, the fight against climate change is one of the priorities we must face, even before facing the announced exhaustion of fossil fuels and the consequent transition towards renewable energy consumption. From a multifactorial analysis, all disciplines agree on the urgency of change and at a global level, this conviction should equally transform our life styles by integrating ecosystemic criteria into any new planning.

Recognizing the Anthropocene as the new natural frame as well as the devastating effects that result from it on a planetary scale allows us to make an epochal re-reading of the wild, reversing its meaning since, instead of corresponding to the old colonialist meaning of the uncultured Other, it should be applied to our civilization that in theory is at its peak of development in terms of education and resources: never before so many have had so much and been able to learn so much. 
With regard to this turning point, we ask ourselves what art can do about it, how it could contribute to the visibility of our urgency and to establish a link with the territory, through the necessary elaboration of the ecological grief that the recognition of this new era provokes, avoiding the paralysis and / or headlong rush as evasion tactics.

\section{CONTENIDO.}

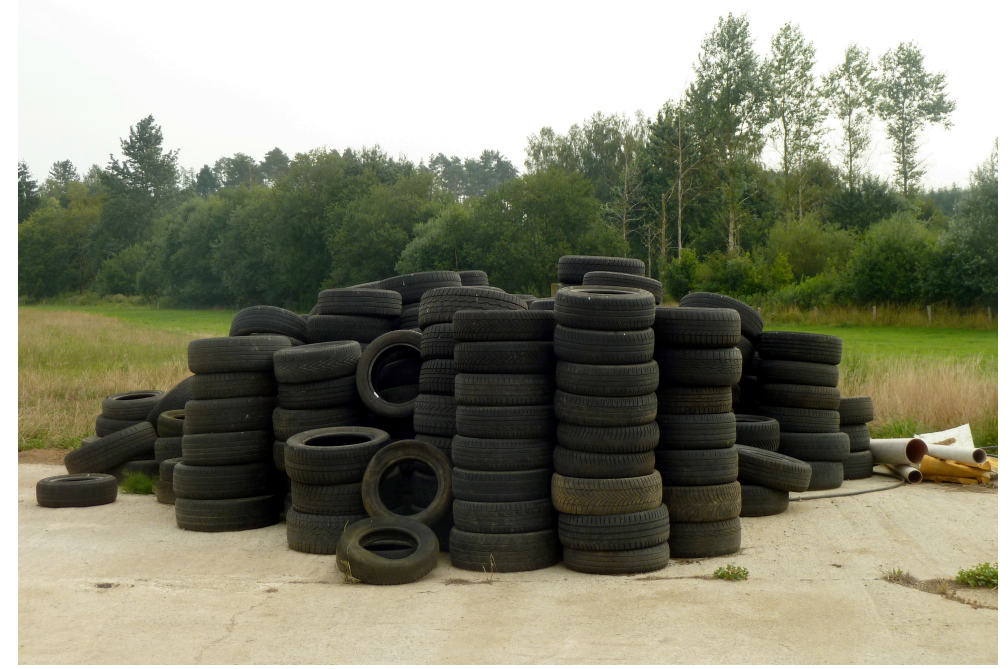

La Campagne, Mijo Miquel (2016)

\section{Bienvenidos al Antropoceno.}

En un momento de crisis sistémica como en el que nos encontramos, resulta redundante incidir en la lucha contra el cambio climático como una de las prioridades a las que debemos atender, incluso por delante del anunciado agotamiento de los combustibles fósiles y la consecuente transición hacia el consumo de energías renovables. No obstante, atendiendo a los retos a los que la humanidad va a tener que hacer frente ya no en un futuro distante sino en uno inmediato, se abren camino las corrientes filosóficas que intentan sensibilizarnos sobre cuestiones como los derechos de los animales no humanos, la necesidad de representación encarnada de los derechos de los territorios o la superioridad existencial de las especies vegetales que, desde que sus antecesoras las cianobacterias establecieron una relación endosimbiótica con protozoos, no han dejado de producir energía y desarrollar estrategias de supervivencia y de expansión exitosas hasta nuestros días.

Estas primeras cianobacterias combinadas empezaron a realizar la fotosíntesis y provocaron la primera gran catástrofe ecológica, el fuerte incremento del porcentaje de oxígeno en nuestra atmósfera con la consecuente desaparición masiva de formas de vida anaeróbicas, ese desastre « natural » que nos hizo evolucionar hacia organismos pluricelulares y que por tanto, nos dio la vida. No es casual la mención de este acontecimiento, el llamado gran evento de oxidación, sucedido hace aproximadamente 2.000 millones de años, puesto que sirve para situarnos en un marco de análisis que muchas veces olvidamos : no somos más que una anécdota en la vida del planeta. La pérdida de centralidad de lo humano nos invita a reflexionar sobre estas grandes transformaciones desde otro punto de vista y a encarar la evolución del planeta, ya instalado en el Antropoceno, con otra perspectiva que podríamos denominar humanismo expandido o post-humanismo, englobando todos estos factores y presencias de forma ecosistémica como única posibilidad de entender, desde estos nuevos materialismos, aquello que nos sucede y aquello que provocamos. Si bien aún se sigue discutiendo sobre la condición, extensión y datación precisa de esta nueva era geológica, el Antropoceno, no hay dudas sobre la huella permanente producida por la humanidad en los sedimentos a nivel global, que es lo que le otorgaría la condición de era y no de mera transformación cultural como pudieron ser el Paleolítico y el Neolítico. Para entenderlo mejor, citaremos las palabras de Alejandro Cearreta, geólogo de la Universidad del País Vasco (UPV/EHU) y único español del grupo de científicos de la Comisión Internacional de Estratigrafía sobre Antropoceno. ${ }^{1}$

\footnotetext{
${ }^{1}$ http://www.ehu.eus/es/web/estratipaleo/alejandro-cearreta
} 
« De las tres hipótesis principales que se barajan, la que se presenta como mayoritaria en nuestro grupo es "la Gran Aceleración": a partir de los años 50 del siglo XX, tras la Segunda Guerra Mundial, todos los indicadores socio-económicos (consumo de agua y otras materias primas, creación de nuevas sustancias y materiales, etc.) se disparan simultáneamente y hay una respuesta paralela de los sistemas terrestres (incremento de gases de efecto invernadero, extinción de especies, deterioro de ecosistemas, etc.) con la destrucción del medio ambiente que se produce en todo el planeta de manera casi sincrónica y simultánea. También está muy ligado al crecimiento exponencial de la población humana (ahora somos más de 7.200 millones de personas en el planeta mayoritariamente viviendo en medios urbanos), a la interconexión mediante dispositivos electrónicos y la rapidez de expansión de las novedades tecnológicas y los procesos «

Los científicos que se resisten a reconocer el Antropoceno argumentan que el registro estratigráfico correspondiente a este corto intervalo temporal es extremadamente reducido y que este cambio responde más a una declaración política que una propuesta científica. Incluso si así fuera, tanto mejor puesto que en lo que sí se ponen de acuerdo todos es que este proceso de transformación no tiene un punto de retorno posible, ni siquiera de preservación de las áreas más remotas, ya que la presencia de todo tipo de materiales y sustancias de procedencia humana (plásticos, cementos, compuestos químicos, etc.) es generalizada incluso en ellas. Por tanto, independientemente de que los científicos determinen que efectivamente constituye una nueva era o que la sitúen bajo el paraguas holocénico, nos parece fundamental entender que nuestra posición al respecto no puede ser únicamente positivista en el sentido de responder o no con rigor a determinados criterios taxonómicos, sino que es una opción inevitablemente política, en la medida en que un reconocimiento de su condición diferencial puede ayudarnos a entender el punto de inflexión histórico/geológico en el que nos encontramos. Y en la medida en que es política, es también económica, fruto de un sistema basado en la expansión e incremento del consumo constantes que no ha cejado en sus objetivos a pesar de la crisis sistémica en la que estamos instalados desde hace más de diez años. Todas las creencias que nos llevaron a esta situación en Occidente siguen inalterables así como las taras acumuladas que produce: la idea central de progreso asociada a la economía y la tecnología exclusivamente, la financiarización generalizada para compensar la pérdida de beneficios, el exceso de producción, el rechazo a asumir responsabilidades ecológicas o sociales como costes reales, la crisis del Estado y la deslegitimación generalizada de las instituciones a diferentes niveles. Y conseguimos a pesar de todo seguir creyendo que nos movemos por consideraciones racionales.

Como plantean los ecólogos y nosotros nos resistimos a contemplar, nos encontramos en un punto en el que se trataría a lo sumo de intentar fracasar mejor en lo que respecta a la humanidad, entendiendo que nuestro futuro está totalmente vinculado al de los territorios y las formas de vida orgánica e inorgánica que nos rodean. En la medida en que nuestros destinos están unidos, nuestra posición de superioridad jerárquica respecto a los demás órdenes de la naturaleza no puede ser mantenida de ninguna de las maneras, al mismo tiempo que no hay posibilidad de identificar e identificarnos con eso natural que creemos real, puesto que es una noción doblemente inexistente ; en primer lugar porque no hay ser humano que nazca fuera de la cultura y en segundo, porque no hay espacio ni especie que no haya sido modificado por nosotros. Por tanto, tenemos varias tareas que afrontar, la primera de ellas reconocer nuestra posición ni siquiera en términos morales, aunque sí, urgentemente, en términos de riesgo directo.

Quizá ello nos permitiera reconocer, a pesar del horror que puede provocarnos, la improbabilidad de nuestra pervivencia y la desaparición de las condiciones de vida que hasta ahora nos fueron favorables puesto que nuestra realidad se está transformando de forma cada vez más acusada en una situación cuya salida pasa por la estrategia del lemming, la eliminación más o menos drástica y voluntaria de una gran parte de la población, o bien por la desaparición total, si persistimos en mantener irresponsablemente nuestras inercias suicidas.

\section{Salvajismos integrados.}

Reconocer el Antropoceno como el nuevo marco natural así como los efectos devastadores que de ello se derivan a escala planetaria nos permite hacer una relectura epocal de lo salvaje, ya que este nuevo mapa conceptual desplaza su sentido original para adquirir otro más punzante. De su origen etimológico, podemos decir que es un adjetivo blanco, casi tierno, que hace referencia a la silva o bosque y se desdobla en silvestre, tal y como indica Miguel Morey (2016). Si bien la flora silvestre mantiene lo inocuo de su significado, "planta que prolifera y se mantiene por sí misma creciendo de acuerdo a sus cualidades innatas" (Snyder, 2016), en el caso de los animales, hace referencia a su naturaleza feroz y ya empieza a darnos pistas del posterior uso que haremos de la palabra. Aplicado al hombre, este adjetivo se tiñe de connotaciones colonialistas en las que se considera inculto todo aquel que no comparte nuestra cultura y por tanto, como las plantas y los animales, necesitado de ser cultivado, domesticado y normativizado. Ya Sebastián de Covarrubias incluye este significado en su Tesoro de la lengua castellana o española (Madrid, 1611) y como Morey se cuida bien de indicar, vincula la palabra a las referencias que desde el arte se han hecho de esta figura estética que habla de aquello que no diferencia al animal del humano.

Este significado se encarna sucesivamente en los diferentes "salvajes" que nuestra civilización va encontrando y automáticamente sometiendo desde la convicción absoluta de su superioridad. Desde los negros de África pasando por los indios del Lejano Oeste y las montañas de cadáveres "salvajes" que dejamos en toda América del Sur. Nos fue tan útil esta denominación que nos costó muchos siglos abandonarla, aún cuando se aplicara junto con el adjetivo "buen" que transformaba la conquista del 
animalesco salvaje en salvación paternalista. No hay mejor para mantener el privilegio de unos derechos que la convicción de la superioridad, como bien sabemos las mujeres. $Y$ una vez domesticados, salvajes y mujeres, podremos volver a asilvestrarnos pero ya no, nunca, quitarnos los sedimentos que nos han ido cubriendo, el mercurio, las materias plásticas, la podredumbre. No hay vuelta atrás, no hay Arcadia ni en este planeta ni en los siguientes, por lo que la desaparición de lo anteriormente entendido como salvaje debe adquirir hoy día un nuevo significado como indica Liz Wells (2011), extendiendo su definición hasta abarcar devastadas áreas industriales, minas abandonadas, centros comerciales cerrados, centros históricos ruinosos e incluso ciudades enteras como Detroit.

Si la ruina post-industrial es una nueva imagen de lo salvaje, no hay imagen más actual que los niños harapientos extrayendo coltán de abruptos túneles, pues feroz es la civilización que explota a niños y tierras para poder esclavizarse mejor a un medio de comunicación/control. Por ello, la relectura de lo salvaje en este momento correspondería a la deriva que nuestra civilización está tomando. Feroces son esas nuevas formas políticas que suceden al capitalismo neoliberal y que desregularizan el "gobierno de lo salvaje" que predicaba Hobbes cuando planteaba la necesidad de un Leviathan que domesticara la natural condición humana. Debemos suponer que si la forma del Estado-nación es otra Arcadia que se hundió en los océanos, las formas actuales de gobernanza o más bien, desgobernanza, permiten vaticinar lo peor, como hemos visto claramente en Rusia en donde los envenenamientos por polonio-210 y otro tipo de argumentos disuasorios de similar calibre nos dan la medida de la razón deliberativa que gobierna allí.

De la misma manera, los planteamientos ecológicos pueden fácilmente derivar hacia el mismo tipo de barbarie. El índice de saturación del planeta es difícilmente calculable pero lo que resulta indudable es que en el Antropoceno, las condiciones de vida van a ser cada vez más complicadas: desaparición de combustibles fósiles, encarecimiento del consumo energético, incremento de la contaminación generalizada y sus efectos sobre la salud, modificación de las pautas de trabajo transformado en un bien escaso y casi siempre precario, crecimiento progresivo de los nacionalismos al que ya asistimos, fenómeno frecuentemente asociado a la crisis económica sostenida como forma de sometimiento, así como la imposición de potencias corporativas como reguladoras de las relaciones internacionales, todos ellos elementos que componen nuestro paisaje inmediato (Davies, 2010).

En ese marco, los criterios ecológicos puede servir de coartada para la extensión de la ferocidad: la versión más dura de la ecología restrictiva que condena a los países del tercer mundo a pagar los costes de la contaminación sin haber recibido los beneficios de la industrialización, la aniquilación de derechos y posibilidades de todos aquellos que no puedan pagarse un entorno sin contaminar, cuando la energía y el agua se conviertan en bienes escasos, la consecuente generación de una clase enferma sacrificada como sobrante, la natural selección de los « mejores " como continuidad conceptual, por no hablar de los animales no humanos o los territorios. No es un panorama muy tranquilizador pero lamentablemente resulta bastante verosímil a corto plazo.

\section{La melancólica belleza y otras estrategias afectivas.}

Robert Adams (1996) habla de la dificultad cada vez mayor que tenemos para relacionarnos con la belleza, de cómo la contemplación de un paisaje bello no está exenta de melancolía ni de un claro sentimiento de derrota, de fragmento que nos recuerda lo que hemos perdido. "Los espacios preservados nos entristecen porque ya no son verdaderos", dice exactamente aludiendo a esa imposibilidad antropocénica de encontrar lugares inmarcesibles. La melancolía del "ya no podemos hacer nada " se suma al distanciamiento que, según John Fowles (2015), se produjo a partir del momento en el que las ciencias ocuparon el territorio y convirtieron nuestra contemplación del entorno en un estudio de campo. Nuestra mirada taxonómica desde el positivismo sin complejos nos ha llevado a distanciarnos de eso que llamamos naturaleza y ante la que nos situamos fuera, pero es que ya no hay un afuera como ya no hay naturaleza. Lamentablemente, en este proceso no es la razón deliberativa la que responde a la catástrofe sino el impacto emocional que nos lleva a asumir sin modular y sin resistir la idea de su desaparición (Snyder, 2016). Deberíamos encontrar estrategias de representación que, aun estableciendo un vínculo efectivo con los lugares, nos acorden la distancia necesaria para poder mirar aún parcialmente nuestra realidad, para no quedarnos congelados en una mueca de horror. Pero, ¿cómo puede el arte hacer una relectura de lo salvaje?, ¿cómo puede contribuir a la elaboración del duelo desde la representación de esa ausencia en su totalidad?

Tal y como Wells (2017) indica, a menudo la manera de establecer vínculos con el territorio pasa por entrar en contacto con las historias visuales o verbales que se traman en ellos lo que supone desde el punto de vista del artista, trabajar la narración de los espacios sin caer en lo espectacular de la ruina de la catástrofe, escapando a la tentación de lo sublime publicitario, para otorgar carne a un lugar, tejido, trama. Cuando Yi-Fu Tuan (1977) reflexiona sobre qué es lo que hace que un lugar sea un lugar y no un espacio cualquiera, nombra toda una serie de factores a veces concomitantes, a veces antagonistas: las fronteras administrativas, por supuesto, con sus nombres y apellidos, servidumbres y pertenencias; la existencia de espacios singulares como montañas y ríos, sus formas físicas diferenciables; la presencia de marcadores externos como estatuas o construcciones normalmente asociadas a memorias históricas, narraciones del poder; la realización de rituales sociales que permiten habitar el territorio (procesiones, patronos, fiestas municipales), conceptos como el de vecindario y por supuesto, las horas y los días que ocupamos transformando ese espacio en algo mejor, estrategia puntera de apropiación y de construcción o mantenimiento de un territorio común. En términos de producción artística, quizás nos sirva reflexionar sobre la idea de cultura como cultivo de una determinada sensibilidad para el mundo tal y como proponía Schiller en sus Cartas para la educación, idea que heredamos del romanticismo alemán. Sin ser ya románticos, 
impulsados por nuestras propias tragedias racionalmente planificadas, sin noción de nación ni casi de territorio, nómadas migrantes, ¿cómo recuperamos la idea sensible de que el planeta entero es nuestra casa?

Estamos aprendiendo nuevas maneras de hablar en esta Babel hiperconectada, pero también en nuestra cotidianidad a pie de calle, a combinar a nuestro favor los nuevos modos de lo local globalizado, y vemos surgir iniciativas artísticas que responden a algunas de estas cuestiones. En concreto, vamos a poner dos ejemplos actuales de artistas que están trabajando a escala tanto local como global y que intentan cultivar una "determinada sensibilidad para el mundo" que, sin ocultar la derrota, nos permita continuar tejiendo vínculos y encontrar incluso salidas tímidas hacia un futuro posible. Expondremos primero una de las piezas de Marco Ranieri ${ }^{2}$ llamada "Herbario urbano" ${ }^{3}$ que él mismo describe de la siguiente manera:

Dentro del espacio urbano, los solares no edificados y/o en desuso, son hot spots de biodiversidad que ofrecen cobijo a numerosas especies vegetales espontaneas. Este proyecto analiza dos áreas específicas de Valencia (una en el casco antiguo y otra en el Cabanyal) que albergan varios solares en un espacio reducido, poniendo en evidencia como las calles que los comunican sirven de corredor biológico para las plantas, que brotan en cada puñado de tierra acumulado en un rincón, grieta o fisura. En cualquier lugar mínimamente favorable a la vida.

\section{Procesos del proyecto:}

1- Analizando imágenes de vista aérea, se han localizado sectores que presentan una elevada concentración de solares no edificados y/o en desuso.

2- A través del trabajo de campo, se ha seleccionado un grupo de solares que por su cercanía y similitud, evidenciaban poder comunicase.

3- Sucesivamente se han investigado las zonas en la cual se encuentran los solares elegidos, recorriendo las calles, observando atentamente en busca de vegetación espontanea.

\section{4- Encontrados los corredores biológicos que los ponen en comunicación, se han marcado los recorridos.}

5- Se han fotografiado e identificado las plantas presentes, colocando en sitios relevantes de los recorridos la descripción de las mismas.

6- En el ámbito de los festivales "Intramurs" y "Cabanyal Intim" se han realizado recorridos guiados contando informaciones y anécdotas.

\footnotetext{
${ }^{2}$ http://marcoranieri.org/about-Marco-Ranieri

${ }^{3}$ www.herbario-urbano.blogspot.com.es
} 


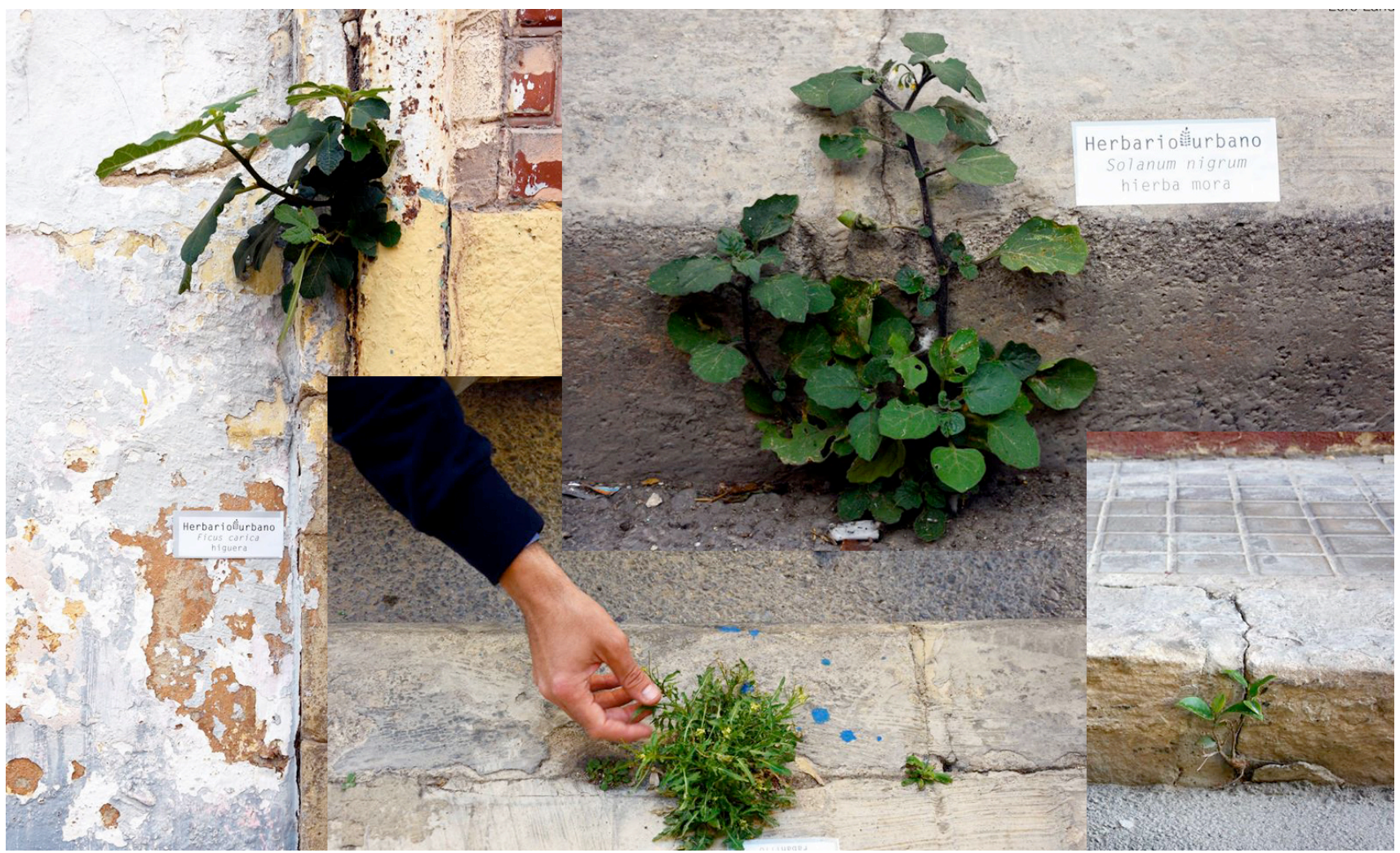

Ranieri lleva a cabo estos itinerarios guiados por la microflora urbana como manera de hacer posible la vinculación con el territorio, la valoración del residuo, el intersticio, lo mínimo, para impedir que nadie pueda estancarse en ese "ya no hay nada que hacer" del que hablábamos antes, realizando una defensa de la naturaleza urbana en su fragmentariedad. Es un artista que invita a trabajar la atención, cuidar lo ínfimo para pasar de una mirada victoriosa a una victoria mínima. Específicamente en este caso, su obra hace que el lugar vuelva a ser lugar mediante la combinación del descubrimiento de formas físicas (corredores biológicos), la presencia de marcadores externos (la flora que responde a una orografía propia), la realización de un ritual mediante un itinerario compartido y la apropiación por el nombre. Mediante el estudio y la consideración de la ciudad como un hábitat natural donde también suceden germinaciones, colonizaciones vegetales, y conexiones entre solares, consigue mostrarnos ese tercer paisaje al que alude Gilles Clément, que reconozcamos las ciudades como espacios también de vida orgánica, ecosistémicos. Ello permite elaborar en cierto modo el duelo y valorar todo espacio como natural, en vez de realizar la operación inversa, educando esa sensibilidad de la que hablábamos, combinando el saber taxonómico del nombre latino y la relación desde la cotidianidad que supone su nombre común con el ritual social del itinerario compartido, alimentando el deseo de reforestar la ciudad.

Escif $^{4}$ es el otro artista del que vamos a hablar y constituye un ejemplo perfecto de nuevas maneras de visibilizar la encrucijada común en la que nos encontramos y de abrirnos hacia esa transición inevitable a la que tenemos que hacer frente. En concreto, nos gustaría compartir su proyecto Breath $^{5}$ en el que, usando una estrategia similar a la utilizada por Pere Jaume cuando se reivindica como despintor, dibuja en una montaña lo que de normal aparece en una pantalla (el nuevo lienzo), utilizando árboles para hacerlo.

\footnotetext{
${ }^{4} \mathrm{http}: / /$ www.streetagainst.com/

${ }^{5} \mathrm{http}: / / \mathrm{www} \cdot$ breathproject.it/
} 


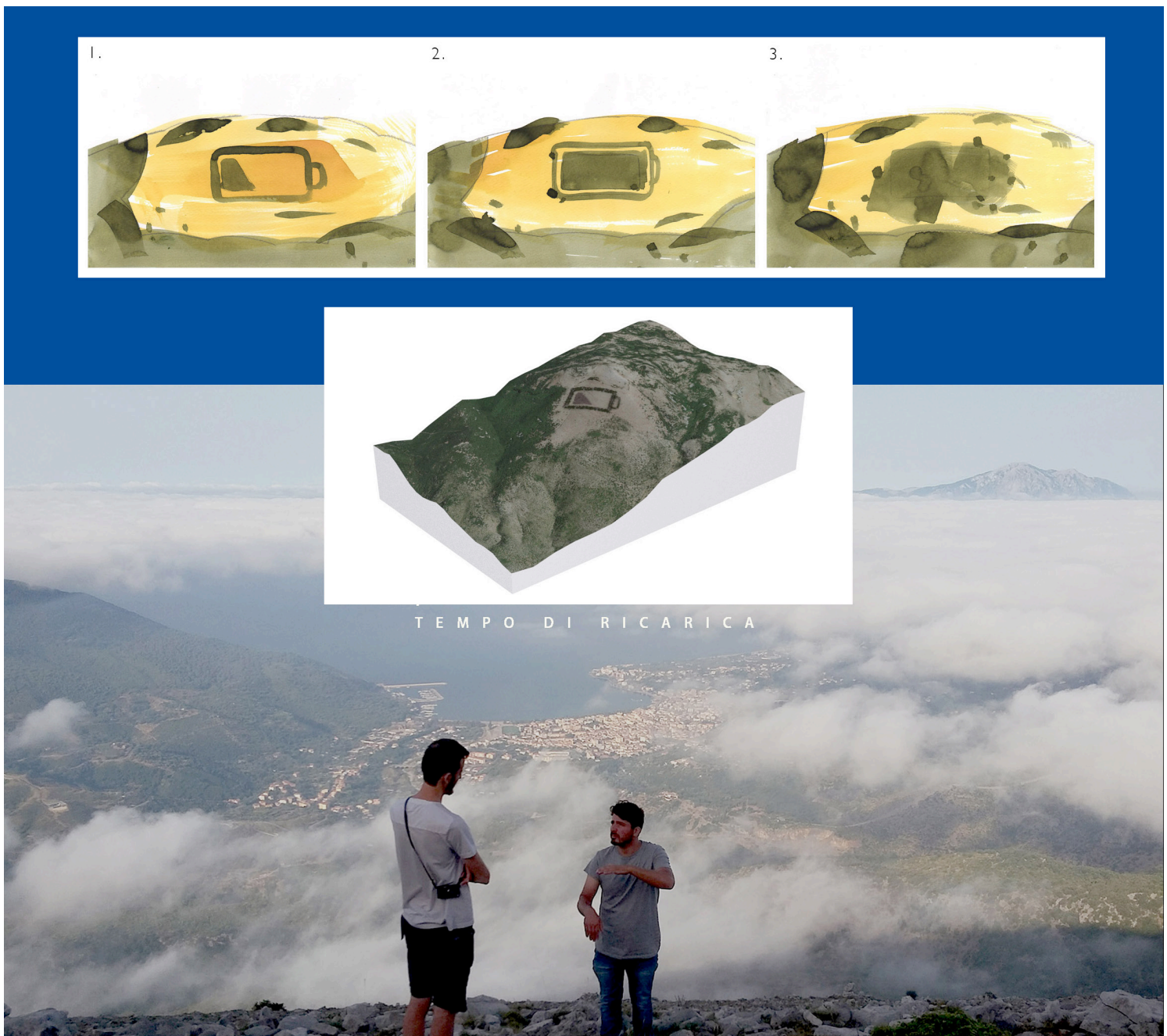

La descripción del proyecto realizada por el propio artista es la siguiente:

BREATH es una obra conformada por 5.000 árboles plantados en el Monte Olivella, que se eleva hasta 1.025 metros por encima del Golfo de Sapri. Una intervención única en la historia, por su género y dimensiones. Es el resultado de estudios de factibilidad realizados durante dos años, cubrirá una superficie de $120.000 \mathrm{~m}^{2}$ y será visible desde una distancia de muchos kilómetros, desde el mar y las ciudades vecinas. BREATH se iniciara con el dibujo de una batería realizado con árboles, representando el ciclo de energía. Seguirá los ritmos del tiempo y de la tierra, renovándose y regenerándose constantemente en continua transformación.

El objetivo principal es REFORESTAR la montaña entera. Desgraciadamente, vivimos en tiempos muy locos, así que sería muy complicado conseguir financiación directa para hacerlo por lo que vamos a intentar algunos trucos. El arte es tan sólo una excusa para llevar a cabo el proyecto. Si todo funciona tal y como deseamos, dentro de unos años, el Monte Olivella tendrá miles de árboles nuevos y no quedarán huellas del hombre.

Fase 1: Plantamos 5.000 árboles para trazar la batería

Fase 2: Plantamos, al menos 2.000 árboles más para rellenar la batería

Fase 3: Dejamos que la naturaleza siga su curso haciendo lo que mejor sabe hacer: crecer libremente y eliminar cualquier huella humana. 
Desde luego, Escif sabe cómo convertir un lugar en el lugar. Siguiendo el análisis de Yi-Fu Tuan, crea un espacio singular de formas físicas diferenciables que, simultáneamente, es un monumento simbólico. A su vez, este símbolo (la batería) visibiliza la necesidad de "recargar" el planeta que pasa por la plantación de árboles gracias a los que podemos captar la energía y transformarla en alimento los productores secundarios del ciclo ecosistémico. Este espacio de recarga constituye también un espacio ritual que el artista activa mediante visitas a la cumbre, el apadrinamiento de árboles y otras actividades de vinculación directa con el procesoabiertas a la participación y difundidas a través de las redes sociales. El sistema de crowfunding combina la obtención de diferentes recompensas con estas actitvidades e incluso con la reforestación de la montaña, dándole espacio a la creación de un bien común conjunto entre personas anónimas. Este hecho y la dimensión de la imagen convierten la obra en el tipo de intervención que podría ayudarnos a trascender el duelo ecológico ya que en sí misma, además de constituir una pieza artística, contribuye a mejorar el entorno al mismo tiempo que no lo disfraza de "natural". En términos planetarios, también es un excelente ejemplo de la combinación de escalas local/global ya que el uso de herramientas virtuales multiplica enormemente su alcance y evidencia a primera vista la cuenta atrás en la que os encontramos: o recargamos o nos apagamos. Cuanto antes seamos capaces de verlo, antes seremos capaces de "fracasar mejor": somos nosotros los que vamos a tener que hacer el trabajo natural revirtiendo los efectos salvajes que hemos causado y demostrando que, a pesar de hacer tan poco uso de nuestro raciocinio, somos capaces de salvar nuestra piel.

\section{FUENTES REFERENCIALES.}

ADAMS, R. (1996). «Truth and Landscape », en Beauty in Photography. Nueva York: Aperture.

CLÉMENT, G. (2004). Manifeste du Tiers Paysage. Paris: Éditions Sujet/Objet.

CUNSOLO, A. (2017). « Mourning Nature : the Mental Health Impacts of Ecological Grief » en Mourning Nature. Hope at the Heart of Ecological Loss and Grief, Ashlee Cunsolo, Karen Landman. Montreal : McGill-Queen's University Press.

DAVIES, M. (2010). « ¿Quién construirá el arca ? » en New Left Review, vol. 61, enero-febrero 2010. Madrid : Akal Ediciones.

DOUGLAS, A. (2016). "Leading cultures of transition through arts practice » en Seminario sobre Arte y Ecología, 28-30 Noviembre 2016, Valencia.Disponible en https://openair.rgu.ac.uk/handle/10059/2059 [consulta : 10 enero 2016] .

FOWLES, J. (2015). El árbol. Madrid : Impedimenta.

HOBBES, T. (1989). Leviathan. Madrid: Alianza.

LANE, N. (2015). Los diez grandes inventos de la evolución. Barcelona : Ariel.

MANCUSO, S. y VIOLA, A. (2015). La inteligencia de las plantas. Barcelona : Galaxia Gutemberg.

MOREY, Miguel. « La leyenda salvaje » en Exit: imagen y cultura, №. 63, 2016, pp. 16-33.

SCHILLER, F. (2005). Cartas sobre la educación estética del hombre. Barcelona: Anthropos.

SNYDER, G. (2016). La práctica de lo salvaje. Madrid: Varasek.

YI-FU TUAN (1977). "Visibility: the Creation of Place" en Space and Place. London \& Minneapolis: University of Minnesota.

WELLS, L. (2011). Land Matters, landscape photography, culture and identity. London: I B Tauris.

(2017). Historias sedimentares. Sobre el espacio y el lugar en las fotografías de Bleda y Rosa. Valencia: Fundació Per amor a l'art. 